\title{
Sexual Attractiveness: a Comparative Approach to Morphological, Behavioral and Neurophysiological Aspects of Sexual Signaling in Women and Nonhuman Primate Females
}

\section{Bernard Wallner, et al. [full author details at the end of the article]}

Received: 21 September 2018 / Revised: 8 March 2019 / Accepted: 13 March 2019 /

Published online: 28 March 2019

(C) The Author(s) 2019

\begin{abstract}
Objective and Methods This review focuses on comparative data in nonhuman primates and humans in relation to signaling secondary sex characteristics (SSC), sexual behavior, and neurophysiology of sexuality during the female cycle.

Results In monkeys and apes no clear distinction can be drawn between sex as a reproductive, social, or a pleasurable activity. Although female sexual behavior is not limited to a specific phase of the menstrual cycle, changes in body morphology and in behavior and psychology (for example, in feeding, risk taking, and mood) can occur across the cycle. In human and nonhuman primates, homologous biological mechanisms including specific areas of the brain, sex steroids, and receptors are involved in regulating female sexuality. Important aspects of this regulation include the interaction between the subcortical reward system and the social brain network and its projection to the prefrontal cortex. In humans, females advertise SSC permanently after the onset of puberty, but without significant changes across the cycle, whereas in other primate species, female sexual signaling can vary significantly across cycle stages and in fertile and non-fertile phases of the life cycle. Conclusion A great deal is now known about the regulation of female sexuality in primates and the use of sexual signals in terms of their variable expression and their information content for males. Human research has also elucidated the cultural mechanisms through which women communicate about their sexuality, including clothes and make-up. A full understanding of female sexuality in humans, therefore, requires knowledge of culture-biology interactions.
\end{abstract}

Keywords Comparative primatology $\cdot$ Sexual attractiveness $\cdot$ Neurophysiological organization $\cdot$ Behavior

\section{Introduction}

Female ovarian cycles have been thoroughly studied in many species of mammals. A great deal of research on endocrine mechanisms in relation to behavioral expression 
rates throughout different cycle stages has elucidated both the proximate regulation and the functional significance of female sexual and reproductive strategies in mammals. Female sexuality involves complex interactions between neuroendocrine mechanisms in relation to neurotransmitter activities to modulate behavior. Such neurophysiological processes are only partially understood in primates.

In most mammals, sexual activities are limited to the periovulatory period of the female cycle. This period is characterized by elevated estrogen concentrations leading to ovulation, followed by an increase of progesterone secretion that facilitates the implantation of the egg into the uterus. In general, sexual activity is correlated with estrogen increase and is reduced at elevated progesterone levels. The period of the cycle in which females are sexually receptive and sexually active is termed estrus.

The best-investigated female sexual behavior in terms of physiology and neurobiology is the lordosis reflex in rodents. This is a posture in which females allow male intromission. Shortly before ovulation, males approach their mating partners and mount them. This sensory interaction enables the lordosis reflex, which is controlled by the sex steroids estradiol and progesterone. The behavioral aspect of this reflex is regulated by subcortical hypothalamic brain structures such as the ventromedial nucleus and the periacqueductal gray, where ovarian hormones find acting sites to facilitate the reflex (Flanagan-Cato 2011; Uphouse 2014). The regulation of lordosis behavior involves complex neurobiological circuits and their underlying neurochemistry. As illustrated by Beach (1976), females advertise their sexual readiness to males with their attractiveness, followed by proceptivity (behavioral signals to males such as solicitation to copulate), and then by receptivity to copulatory behavior with subsequent ejaculation.

These three aspects of female sexuality are related to hormonal changes during the female cycle and ultimately serve the process of reproduction. The Beach paradigm was thought to encompass more or less all non-primate mammalian species. In primates, instead, it has long been known that females do not limit their sexual behavior to specific cycle stages and to the corresponding hormone fluctuations (Dixson 2009). In humans in particular, copulations can occur during all cycle stages (Dixson 2009). This has led some to believe that human sexuality is completely emancipated from its biological regulation and entirely dependent on volitional and cultural factors. It is, however, very unlikely that humans continued to evolved by natural selection up to the Pleistocene, but then suddenly stopped after settling and farming (approx. 10,000 years ago). Rather, it is more likely that cultural and genetic processes mutually interacted throughout all human evolution (Richerson et al. 2010). Natural selection is still acting on certain traits in contemporary humans (Byars et al. 2009) and producing adaptations through culture-gene co-evolution. This process may operate much more quickly than previously thought (Field et al. 2016). Although there are some important differences between human female sexuality and female sexuality in nonhuman animals, the prevalent view emphasizes continuity rather discontinuity between humans and other animals, especially other primates. Therefore, in this article, we highlight the many similarities between humans and nonhuman primates in hormone secretions, neurophysiological subcortical organization, and female sexual behavior during the reproductive cycle, with particular emphasis on the signaling of Secondary Sexual Characteristics (SSC). 


\section{Hormones, Behavior and SSC}

In nonhuman primates, similar to other mammals, during the female's cycle, sex steroid hormones are regulated by the release of the pituitary gland peptides folliclestimulating hormone (FSH) and luteinizing hormone (LH). FSH stimulates the growth of the sex cells, the ovarian follicles; LH in high concentrations induces ovulation in Graafian follicles that have been primed with FSH. Data on rhesus macaques show that preovulatory LH and FSH peaks affect estradiol increases and thus represent important prerequisites for a successful ovulation (Dixson 1998). More than 40 years ago, Dixson et al. (1973) reported not only a periovulatory increase of estradiol in primates, but also a similar peak of the androgen testosterone. Later, Nadler et al. (1985) demonstrated an association between estradiol and testosterone concentrations during the mid-cycle phase and maximum perineal swelling size in the common chimpanzee. Moreover, the mid-cycle estradiol and testosterone peaks in chimpanzees are comparable to those in women (Morris et al. 1987).

\section{The Three-Fold Impact of SSC in Nonhuman Primates: Attractiveness, Fertility, and Sociality}

Females of many nonhuman primate species exhibit sexually attractive signals during their cycle. The most prominent signals are coloration and/or perineal swelling. The coloration and degree of anogenital swelling size may affect the vulva area, the clitoris, to some extent the perineal region, and the area around the ischial callosities (Dixson 1983). Both coloration and perineal swelling can vary dramatically among females in a group. Their expression rates are controlled by the sex steroids estradiol and progesterone. Estradiol enlarges swellings by transferring water into the intercellular tissue, and an increased blood flow causes more intensive coloration (Bradley and Mundy 2008). After ovulation, the luteal steroid progesterone reduces the swellings (Wildt et al. 1977). Both the intensity of coloration and the size of the swelling are most pronounced during the periovulatory period (Wallner et al. 2011; Möhle et al. 2005).

These periods are correlated with the highest copulation frequencies, and the probability of fertilization is highest as well. Nonetheless, studies on Barbary macaques indicate that sexual interactions are not limited to the periovulatory period and are therefore displayed independently of the probability of fertilization, e.g., pregnant females with perineal swellings can copulate as much as non-pregnant ones (Küster and Paul 1984). However, fluctuations in swelling size and/or coloration are often correlated with low sex hormone secretion rates and with sexual behavior. Lactating females too can show sexual solicitation behavior and copulations (Brauch et al. 2007). A comparison between non-lactating and lactating females in Japanese macaques revealed more intensive red coloration and copulations (with and without ejaculations) for non-lactating females during sexually active periods (Wallner et al. 2011). However, copulations (with and without male ejaculation) were not uncommon among lactating females, although they showed slight changes in coloration intensity and their sex steroid production was significantly lower compared to non-lactating females. Less well-understood is the functional significance of changes in coloration intensity and size of the perineal swellings in Tibetan macaques, as females in this species do not exhibit any typical behavior associated with estrus and they copulate frequently outside 
the mating season (when SSC are not obviously expressed) (Li et al. 2005, 2007). Nonreproductive copulations were not observed in pregnant or lactating individuals and typically involved adolescent males. Such copulations often occurred after social conflicts, whereby females approached males and solicited copulation, suggesting a social function of sexual behavior (Li et al. 2007).

Ovariectomy does not suppress female sexual behavior in Old and New World monkeys. In stumptail (Baum et al. 1978) and rhesus macaques (Chambers and Phoenix 1987) ovariectomized females show some sexual receptivity, and in the common marmoset (Kendrick and Dixson 1984) males still exhibit high copulation frequencies with ovariectomized females. Baboon females that had been ovariectomized hardly drew the attention of singly housed males when placed in visual, olfactory, and auditory contact with them (Girolami and Bielert 1987). Nonetheless, if the same females were provided with large artificial swellings, then the males became sexually aroused and masturbated.

Masturbation is not unique to humans (Dixson 1998), but self-stimulation of genitalia is nearly exclusively reported in Old World monkeys and apes (Dubuc et al. 2013). This type of behavior is shown under captive, semi-free, and wild conditions. Barbary macaque females implanted with contraceptives exhibit perineal swellings during non-sexual periods. Males seemed to be more attracted to females with enlarged swellings (Wallner et al. 1999). They inspected — sniffed and touched - the anogenital region of these females and masturbated frequently in their presence. Almost no mounting behavior was performed, suggesting that visible sexual traits stimulate self-directed sexual behavior in males (Wallner, pers. obs.).

A study on same-sex mounting behavior in Japanese macaque females showed that females were able to self-stimulate their vulvar, perineal and anal (VPA) regions. Females also mounted other females and while doing so, they rubbed their VPA on their partners or stroked their VPA with their own tail (Vasey and Duckworth 2006). Because the VPA region mediates sexual arousal in both humans and in nonhuman primates, the authors of this study interpreted the behavior of macaque females as providing an immediate sexual reward. Such sexual sensation from genitalia activates the mesolimbic brain areas (Georgiadis and Kringelbach 2012), resulting in the perception of pleasure. Early research suggested that nonhuman primates mate exclusively in a dorso-ventral position, whereas humans prefer face-to-face sexual intercourse to facilitate female orgasm. Early studies also suggested that that nonhuman primate females are not able to experience orgasm. Both suggestions proved wrong: lesser and great apes engage in face-to-face copulation, and female orgasm has been recently reported in a number of monkey species (Dixson 2009).

Bonobos display unique patterns of socio-sexual behavior for nonhuman primates. In bonobos, sexual interactions occur daily, and independent of female cycle stages and therefore of reproduction. Sexual interactions involve a variety of sexual behaviors and include individuals of all age and sex combinations (Manson et al. 1997). Chimpanzees also exhibit perineal swellings beyond ovulation periods. Wallen and Zehr (2004) noted, "The system of hormonally modulated sexual motivation combined with a physical capacity to mate at any time has evolved in primates to balance the social and reproductive uses of sex." This clearly applies to female sexuality in great apes such as bonobos and chimpanzees. In orangutans, females do not express SSC, suggesting that ovulation is concealed (Pawlowski 1999). Knott et al. (2010) 
investigated sexual interactions in Bornean orangutans. Near ovulation, females copulated with dominant, flanged males with large cheek pads, but during cycle stages with low probability of fertilization, females preferred less dominant, unflanged males. The authors suggested that in a species with concealed ovulation where males use frequent sexual coercion, such female sexual strategies may minimize male aggression. Differentiated female preferences for mating with adult and adolescent males at different cycle stages was also reported in Phayre's leaf monkeys. During periovulatory periods (POP), females were more proceptive and receptive to adult males, but they preferred adolescent males during non-periovulatory periods (NPOP). Interestingly, adult males seemed to recognize female fertility better than adolescent individuals did ( $\mathrm{Lu}$ et al. 2012). Another study investigated female chimpanzee mating preferences during POP and NPOP. Female proceptivity correlated with male mating success and female resistance behavior reduced male mating success, during POP. Proceptivity was also positively related with male mating success during NPOP. These data indicate the influence of female choice on male mating success during different cycle stages in chimpanzees (Stumpf and Boesch 2006). In white-handed gibbons, cycling females showed increased group-leading activities compared to pregnant or lactating females. The behavior probably served a non-ecological function, and helped females search for potential mating partners (Barelli et al. 2007).

Female SSC-related signals are attractive to males and may stimulate male sexual arousal. Females, in turn, may benefit from received increased social and sexual attention from males. For example, Barbary macaque females implanted with contraceptives can develop enlarged swellings during non-reproductive periods and, if so, they have more affiliative interactions and fewer agonistic interactions with males, and they receive more agonistic aid and more grooming from males (Wallner et al. 1999, 2006). Similarly, female chimpanzees with swellings enjoy significantly more social benefits than those without swellings. In addition to their increased affiliative interactions with males, they gain greater access to food resources. Pregnant chimpanzee females with large perineal swellings may find it easier to transfer from one group to another without being attacked by males (Wallis 1982, 1992). Furthermore, baboon males strategically approach swollen females when entering a new group (Goodall 1986), and affiliate temporarily with them.

Why males find SSC signals attractive is more difficult to interpret. In other words, the information content, if any, of these signals remains unclear. Pagel (1994) argued that large perineal swellings are reliable indicators of female reproductive quality and health. Such signals must be the evolutionary result of intra-sexual female competition for males. This reliable indicator hypothesis was supported by data from wild olive baboons, showing that females that exhibited larger swellings during their sexually active periods had more affiliative interactions with males and produced more offspring than females with smaller swellings (Domb and Pagel 2001). Critics of this study, however, were able to show major flaws in the statistical data analyses. Subsequent studies failed to replicate these results and to show better reproductive performance for females with larger swellings (Setchell et al. 2006a; see Fitzpatrick et al. 2015). Nevertheless, there are indications that conceptive swellings are larger than nonconceptive ones and that males do prefer to mate with females during those cycles with higher chance of fertilization (Fitzpatrick et al. 2015). 
With regard to coloration, non-lactating Japanese macaque females had more intense red coloration, especially at the nipple and hindquarter regions, and all of them conceived during the sexually active period compared to those who were lactating (Wallner et al. 2011). In mandrills, multiparous females had brighter faces, possibly signaling their history of successful reproduction and current fertility, than nulliparous females (Setchell et al. 2006b). Rhesus macaque males preferred females with more reddened hindquarters, whereas females paid more attention to faces of males and females with intense red coloration; the latter may be associated with female-female competition as well (Gerald et al. 2007; Dubuc et al. 2016). Similarly, Japanese macaque males were more interested in faces with more intense red coloration, and especially in faces with increased color contrast (Pflüger et al. 2014).

Female SSC signals in relation to ovulation are generally prominent in primate species that live in multi-male, multi-female groups with promiscuous mating systems. In contrast, in species that live in one-male units, with polygynous or monogamous mating systems, SSC signals such as sexual swellings are rare and seem to be less related to advertising female fertility. The ultimate reason for such differences seems to be intrasexual competition for mating partners during periovulatory periods in promiscuous species compared to one-male units (Clutton-Brock and Harvey 1976). An exception to this pattern is the female sexual swelling in the white-handed gibbon, a species living under monogamous conditions. Females exhibit relatively large swellings during the cycle but also during pregnancy indicating that these signals are not a precise indicator of fertility and that males may be unable to detect ovulation from these signals alone (Barelli et al. 2007).

\section{Women: Behavioral and Morphological Variation}

Women's sexual behavior may fluctuate significantly during their cycle. Burleson et al. (2002) investigated allosexual and autosexual behavior in heterosexual and lesbian women with or without a partner. Allosexual behavior increased during the follicular and ovulatory phases in women living with a partner compared to those without a partner. In contrast, the frequencies of autosexual behavior were elevated during the follicular and ovulatory cycle phases in both heterosexual and lesbian women living without a partner vs those with a partner. A longitudinal study of female sexual behavior during five cycle phases - namely menstrual, postmenstrual, ovulatory, luteal and premenstrual - showed peak sexual activities during ovulation (Harvey 1987). That study used temperature charts to identify different cycle stages. A more recent investigation assessed sexual activities in relation to the preovulatory LH increase. Women initiated more sexual activities during the preovulatory LH surge and showed increased sexual desire and fantasies 3 days earlier (Bullivant et al. 2004). Pillsworth et al. (2004) showed that sexual desire in paired women was mainly expressed during the periovulatory phase, and that among these women increased conception probability was correlated with sexual desire. Interestingly, the duration of partnership was positively related to sexual desire in extra-pair-relationships during periods of increased fertility. Another study on sexual fantasies in relation to menstrual cycle phases in single-living women showed increased sexual fantasies during preovulatory elevated LH secretion; these fantasies decreased after ovulation (Dawson et al. 2012). During follicular and periovulatory periods the number of sexual fantasies 
increased while emotional content increased in conjunction with ovulation (Dawson et al. 2012).

It has been argued that during fertile cycle phases, paired women may engage in short-term extra-pair relationships to mate with partners of high genetic quality (such as high testosterone levels, masculinity, dominance, symmetry) (e.g., Gangestad and Thornhill 2008). Two recent meta-analyses of these studies, however, provided mixed support this conclusion (Gildersleeve et al. 2014; Wood et al. 2014) and subsequent, rigorous investigations have failed to replicate some of the initial findings (Jones et al. 2018a, b; Jünger et al. 2018). Evidence concerning the influence of hormones on sexual desire during different cycle stages seems to be also conflicting. Roney and Simmons (2016) found a significant negative correlation between progesterone increases and women's desire for their partner and other men. In contrast, mid-cycle stages were related to high extra-pair and in-pair desire, although the correlation between desire and estradiol was only marginally significant. Contrary to these results, another study showed that higher estradiol levels are associated with an increased extra-pair sexual interest, whereas higher progesterone concentrations predict greater in-pair interest (Grebe et al. 2016). Finally, recent studies have provided some further conflicting evidence as to whether changes in estradiol and progesterone concentrations across the cycle are associated with changes in female general sexual desire vs female desire for particular types of sexual relationships (Jones et al. 2018a; Shirazi et al. 2019).

Many studies of women's mate preferences in relation to the menstrual cycle compare fertile vs luteal phases. During fertile periods, women do generally prefer masculine men who are assertive and competitive, have lower voices, or scents associated with body symmetry (Gangestad et al. 2004; Garver-Apgar et al. 2008). For example, in one study, women's preference for male scents related to symmetric body features was positively related to women's estrogen and testosterone levels, but negatively to their progesterone (Garver-Apgar et al. 2008). Furthermore, women with lower urinary estrone-3-glucuronide concentrations showed stronger cyclic shifts (nonfertile/fertile) in their preferences for masculine voices (Feinberg et al. 2006; but see Jünger et al. 2018 for negative results). Finally, cycle stage apparently plays an important role in being motivated to detect erotic stimuli in art. During the first half of the menstrual cycle, women emphasized more erotic stimuli in paintings compared to the second half of the cycle (Rudski et al. 2011).

Aside from behavioral changes, different energetic needs are also evident during the menstrual cycle. Lissner et al. (1988) described two peaks of energy intake during the cycle: the first at the middle of the follicular phase, and the second at the middle of the luteal phase. Especially during the luteal phase, women crave more carbohydrate- and fat-containing food (Davidsen et al. 2007). From a physiological point of view, such food consumption behavior is relevant because energy is needed to produce the endocrine surges necessary for ovulation and for the successful implantation of fertilized eggs into the uterus tissue. Another study showed that consuming sweet food and its preference rating increase during the pre-ovulatory phase (Bowen and Grunberg 1990). Both, nonhuman primates and humans, however, show increased luteal energy intake compared to follicular phases (Dye and Blundell 1997). Czaja and Goy (1975) carried out classical studies on food intake under estrogen and progesterone treatment in rhesus macaques and guinea pigs. In both species, the food intake decreased around the time of ovulation and increased during other cyclic periods. Estrogen administration 
to ovariectomized females showed a clear downregulation of feeding behavior. Ovariectomized females, however, did not change their feeding behavior after progesterone administration compared with control individuals in both species. Most recently, Roney and Simmons (2017) tested hormonal predictors of daily self-reported food intake in naturally cycling women. They reported that estradiol negatively and progesterone positively predicted food intake, and that a decrease in eating during the fertile phase of the cycle was mediated by the two hormones. These associations between hormones and food intake were mirror images of those found for sexual desire, and were very similar to those reported in nonhuman primates.

In addition to sexual desire/preferences and food intake, a great deal of research has documented also changes in mood and cognitive function in relation to the menstrual cycle. Some of this research has involved estrogen replacement therapy (reviewed by Shively and Bethea 2004; see also Voytko 2002, for data in female macaques). In women, the premenstrual syndrome and its association with depression are relatively well investigated (e.g., Forrester-Knauss et al. 2011). Interestingly, Shively et al. (2002) were able to relate lower ovarian function and impaired HPA activity with signs of depression in subordinate macaque females.

\section{Risky Behavior During Menstrual Cycle}

Sexual interactions are per se related to physical risks for both sexes (Wallen and Zehr 2004). For example, T lymphatic viruses are sexually transmitted in humans and in several species of nonhuman primates (see Junglen et al. 2010). Simian and human immunodeficiency viruses (SIV, HIV) are among the most infamous sexually transmitted diseases. The Center for Disease Control and Prevention (https://www.cdc.gov/) has indicated that in the U.S. individuals between 15 and 24 years of age represent $27 \%$ of the sexually active population, yet they account for $50 \%$ of sexually transmitted infections. In their fact sheet of infections, gonorrhea ranks number one (70\%) followed by chlamydia (63\%), HPV (49\%), genital herpes (45\%), HIV (26\%), and syphilis (20 $\%)$. These data, however, do not reveal whether infections are related to specific menstrual cycle stages. Regarding the type of infection, women in the 15-24 years range seem to be most vulnerable to chlamydia infections. Interestingly, some of these pathogens - such as chlamydia (Chlamydia trachomatis) or syphilis (Treponema pallidum) - have also been detected in captive apes (Rushmore et al. 2015), although little research on sexually transmitted diseases has been conducted in wild nonhuman primates.

Molecular immune defense genes seem to evolve faster in promiscuous primate species, and especially in species that live in larger groups (Wlasiuk and Nachman 2010). Nunn et al. (2000) found that white blood cell counts were significantly higher in primate species in which females have more mating partners, and therefore the risk of sexually transmitted diseases is higher. A recent study analyzed the evolution of the seminal protein gene semenogelin 2 (SEMG2) in primates, which is responsible for the semen coagulation rate (Dorus et al. 2004). The results showed that promiscuous species exhibit higher rates of SEMG2 polymorphism, which results in faster coagulation rates. The species with the highest evolution rate is the common chimpanzee. Interestingly, the relationship between the rate of evolution of SEMG2 and residual testis size 
is higher in humans than in polygynous (orangutan, gorilla) or monogamous (gibbon) species (Dorus et al. 2004). A similar correlation is evident between midpiece sperm volume (the location of mitochondria) and residual testis size in humans (Anderson and Dixson 2002). Both results indicate a selection process favoring moderate promiscuity in humans. Based on these findings and the previously mentioned female desire for extra-pair sex during fertile cycle stages, it may be argued that women's fertility periods are associated with risky behavior.

In female baboons, an increased risk of injury (presumably related to reproductive competition) has been documented during days with a high conception probability (Archie et al. 2014). Promiscuous female baboons signal their periovulatory period with exaggerated swellings, which may attract the males' sexual attention but also aggression from males and females. Women seem to have developed strategies to reduce their exposure to risk during fertile cycle periods. During ovulation, women engage in less risky behaviors to avoid sexual assaults (Bröder and Hohmann 2003) and show an increase in handgrip strength in response to a sexual assault vignette, suggesting the existence of behavioral adaptations to reduce the probability of conception as a result of rape (Petralia and Gallup 2002). However, strong individual differences probably exist among women in their tendency to engage in sex-related risky behavior in relation to their age, personality, chronotype (i.e., morningnesseveningness), and hormonal profiles (e.g. Maestripieri 2014). It is possible that variation in female risky behavior during the cycle may be influenced by cortisol and its interaction with sex hormones. A study on a rural Mayan population showed increased urinary cortisol during the follicular phase and between day 4 and 10 after ovulation. Interestingly, higher cortisol during the follicular phase was associated with progestin concentrations, suggesting an impairment of implantation processes (Nepomnaschy et al. 2004).

\section{Women's Advertising During Different Cycle Phases}

Do human females differ from other primate females in advertising their sexual attractiveness in relation to different cycle stages? In contrast to some primate SSC signals such as exaggerated sexual swellings, which fluctuate across the cycle in relation to changes in estrogen and progesterone concentrations (Wallner et al. 2006, 2011), women have permanent developed SSC such as the waist-to-hip ratio, buttocks, and breasts. Nonetheless, cyclic changes in body morphology are evident also in women (reviewed in Farage et al. 2009). Most of these changes are related to physiological parameters such as lipid content of skin, collagen production, pigmentation, hydration, thermoregulation, functional aspects of the immune system or changes of water compartments and subcutaneous fat tissue. Whether these cyclic modifications are detectable by men remains unclear (Puts et al. 2013; for evidence, instead, that cyclic modifications in faces are detectable by women, see Necka et al. 2016, 2018; Hurst et al. 2017; Krems et al. 2016).

Some of the most obvious changes occur in the subcutaneous fat regions of the thighs and abdomen (Perin et al. 1999). In these areas, fat increases up to $4 \%$ during menstruation, and the fat content is lowest during the first half (follicular stage) of the cycle. Fowler et al. (1990) used magnetic resonance imaging to detect changes in the 
female breast volume during the cycle. During the period between day 16 and 28 , which more or less corresponds to the luteal phase, the water content increased by $24 \%$, and parenchymal volume by $38 \%$. In comparison, during menstruation, water content decreased by $17 \%$, and parenchymal volume by $30 \%$. This represents a major volume change for the breast tissue, which is analogous to changes in anogenital swellings in nonhuman primates. However, the volume increase in swellings is mediated by estrogens and is based on a shift of intracellular water into the interstitial tissue, whereas the volume increase in the breast tissue seems to be mediated by luteal progesterone. Whether these subcutaneous fat changes during the cycle are temporal SSC, which signal attractiveness in women remains unclear.

There are, however, hints that women try to enhance their sexual attractiveness during particular phases of the cycle. A study on more than 300 women revealed some associations between clothing preferences, sexual motivation, and hormone concentrations (Grammer et al. 2004). Higher sexual motivation was associated with the tendency to wear sheer clothing (which allows the woman's body or undergarments to be seen through its fabric), whereas salivary estradiol concentrations were correlated with the amount of skin exposure and with clothing tightness. Moreover, women significantly change their consumer behavior across the cycle and spend more time and money on cosmetics, fashion, and jewelry during the periovulatory phase (Durante and Griskevicius 2016; Durante et al. 2010). There is also some evidence that these changes in behavior are influenced by hormones and that they reflect female-female competition for mating partners (Durante and Griskevicius 2016; Durante et al. 2010).

These findings indicate that women are aware of their cycle stage and use their clothes or make-up to attract men's attention on particular body regions such as their lips, breasts, or hips (see Haselton and Gildersleeve 2011). Gait also changes during the cycle, such that particular postures are used that help advertise SSC such as the waist and hips. Guéguen 2012showed that during the periovulatory phase women walk more slowly and that men find this sexier, suggesting that gait is a critical behavior used by women to display and enhance their physical attractiveness. Wearing shoes with high heels may influence the walking performance of women during periovulatory cycle stages. Wearing high heels enables women to change significantly the lumbar curvature and the inclination of the pelvis (Smith 1999). Visually, this yields a posture signaling a hollow-back and exposing the waist and hips more prominently. Evidently, men recognize it as a supernormal stimulus and associate it with female attractiveness. High heels also influence the gait of women by reducing stride length and increasing the rotation of the hip.

In conclusion, advertising physical attractiveness is an important adaptive trait in the context of sexual interactions in many nonhuman primates and in humans. In nonhuman primates living in multi-male multi-female social groups, cycledependent sexually attractive characters are signaled visibly to inform males about female fertility and readiness to mate. In humans, these signals seem to be more cryptic, which could reflect the permanent presence of obvious SSC; this may prevent males from easily recognizing women's fertility. From an evolutionary point of view, concealed ovulation in humans might reduce female-female mating competition and promote greater male investment in women regardless of their fertility and reproductive potential. 


\section{Neurophysiology of Sexual Behavior}

The eighteenth century Venetian Giacomo Casanova stated, "Only man is capable of real pleasure, because he is gifted with the power of thought, and he expects the desire, he studied it, he gives and remembers her, if he has enjoyed it (https://www. aphorismen.de/zitat/67814). Casanova suggests that three main aspects of human sexuality are pleasure, desire, and thought, and implies that human beings are perhaps unique in the animal kingdom in that for humans, sex in mainly in the brain. In reality, the neurophysiological regulation of sexuality shares many similarities in humans and other primates. Pleasure and desire are mainly located in subcortical midbrain structures, which are homologous among primates. Therefore, it is likely that the way human beings desire sex and experience sexual pleasure is very similar to the other primates do it. With regard to thinking about sex, especially conscious thinking, the situation is more complicated, as humans are unique among the primates for having a large neocortex that allows for conscious thinking. The phylogenetic increase in the size of the neocortex from monkeys to apes to humans seems to be related both to the rate of neuronal projections from the midbrain to the neocortex as well as to how the neocortex has evolved (Raghanti et al. 2008).

The vertebrate brain has several areas that regulate the emotional aspects of sex as well as the performance of sexual acts. The comprehensive comparative analysis by O'Connell and Hofmann (2011) pointed out that brain regions representing the social behavior network and the mesolimbic reward system are particularly important for the sensation of pleasure. The size of the hypothalamic nuclei in the social behavior network is sexually dimorphic. The larger male nucleus of the preoptic area (POA) and the bed nucleus of stria terminalis (BNST) are exposed to testosterone during ontogenetically sensitive periods (Hofman and Swaab 1989). Such exposure produces concentration-dependent androgen receptor fields, which are essential for promoting male reproductive behaviors during adulthood. An important functional role of the POA is to integrate external and internal information to facilitate mating behavior and gender identity (Garcia-Falgueras et al. 2011). Research on female macaques has revealed neuronal activity in the ventromedial hypothalamus (VMH) and POA areas during sexual activity (see Dixson 2009). The sex drive in humans and in nonhuman primates is regulated by both androgens and estrogens (Fisher et al. 2006; but see Cappelletti and Wallen 2016).

A dopaminergic influence in the POA on sexual arousal has also been documented (Schober and Pfaff 2007). The mesolimbic reward system is one of the best investigated brain areas in medicine and biology. Comparative studies on fishes, amphibians, reptiles and mammals have revealed analogous functional neuroanatomic structures (O'Connell and Hofmann 2011). The monoamine neurotransmitter dopamine and its two-class receptor system (Missale et al. 1998; Beaulieu and Gainetdinov 2011) are key players in these mesolimbic structures. They mediate pleasure associated with predictive, motivational or attentional sensations in relation to learning processes (Berridge and Kringelbach 2008). The dopaminergic system is linked to the prefrontal cortex to mediate cognitive processes generated subcortically in association with sex-related emotion and behavior. In the prefrontal cortex, the enzyme catechol-omethyltransferase is responsible for deactivating dopamine (Cumming et al. 1992), while the dopamine transporter protein regulates the duration of dopamine receptor 
activation (Giros and Caron 1993). Comparative analyses of cortical dopaminergic innervation in humans and nonhuman primates reveal no quantitative differences between chimpanzees, macaques, and humans. However, the sublaminar patterns of innervation differ in specific areas between humans and the other two species (Raghanti et al. 2008).

The main brain structures of the mesolimbic reward system are the striatum (STR: compulsive behavior), ventral tegmental area (VTA: motivation, reproduction, parental care), medial amygdala (meAMY: aggression reproduction, parental care, social recognition), ventral pallidum (VP: emotional learning, parental behavior), nucleus accumbens (NAcc: emotional learning, impulsivity, motivation, parental care), and the hippocampus (HIP: spatial learning) (see O'Connell and Hofmann 2011; Berridge and Kringelbach 2008). In humans the subcortical and cortical cognitive aspects of sexual pleasure are related to neural activity in the medial orbitofrontal, mid insular, and the anterior cingulate areas (de Araujo et al. 2003). Most of the research on the orbitofrontal cortex has focused on sensory integration and reward value in relation to food (Kringelbach 2005). According to Rilling (2011) the reciprocal behavior of food-sharing among non-related hunter-gatherer populations provides a window into important neurobiological aspects of human social evolution. fMRI studies confirmed that the orbitofrontal cortex is also activated during reciprocal prosocial interactions (Waytz et al. 2012). We argue that in addition to food-sharing and other prosocial behaviors, sexual reward also played an important role in the evolution of the primate orbitofrontal cortex in relation to subcortical brain areas (see Rudebeck and Murray 2011, and Wikenheiser and Schoenbaum 2016). Interestingly, both brain areas - the social behavior network and the reward system - consist of highly interactive nodes and overlapping structures, which represent an integrated evolutionary ancient social decision-making network (O'Connell and Hofmann 2011).

\section{Sex Steroid Hormones and their Receptors}

Sex steroid hormones, in particular brain estrogen concentrations, significantly modulate changes in women's mood, cognition or sexuality across the menstrual cycle. The actions of estrogen in the brain depend on estrogen receptors, which occur in two isoforms: $\mathrm{ER} \alpha$ and $\mathrm{ER} \beta$. The latter mediate subcortical cognition processes between hormonal components and expressed behavior. Patchev et al. (2004) demonstrated that activating $\mathrm{ER} \alpha$ receptors in neonatal female rats resulted in impaired ovarian function and reduced sexual behavior in adulthood. This treatment affected the morphology of the subcortical brain areas such as the periventricular nucleus of the hypothalamus (AVPV; it produces GnRH in humans and nonhuman primates) and POA, namely, it made these areas more masculine. In contrast, activation of $E R \beta$ receptors failed to alter later female sexual behavior or responsiveness to estrogens and did not affect the morphology of the POA. In situ hybridization in ovariectomized and hysterectomized female macaques showed the distribution density of ER $\beta$ mRNAs for subcortical hypothalamic, limbic and midbrain areas. Administering estrogens did not alter overall receptor densities but, progesterone treatment down-regulated the receptor signal in specific hypothalamic and hippocampal regions (Gundlah et al. 2000). Generally, estradiol influences ER $\alpha$ receptors in subcortical areas such as POA and VMH (both areas belong to social behavior network, which coordinates sexual activity and is multi- 
connected with the reward system) in ewes (Fergani et al. 2014). Higher estradiol and lower progesterone concentrations are related to elevated receptor activity and affect sexual behavior under the influence of an LH surge in both areas (Fergani et al. 2014). This scenario seems to be typical for mammalian mid-cycle stages. Similar results were documented for a macaque species, in which estrogen receptor activity was investigated in several brain areas in mated and unmated females. Mated females had significantly increased receptor activities in POA and $\mathrm{VMH}$ regions compared to unmated ones (Michael et al. 2005). Another primate study focused on the $\operatorname{ER} \alpha$ and progesterone receptor density in hypothalamic regions of ovariectomized aged and young rhesus macaque females after long-term estradiol treatment. The hormonal treatment mimicked therapeutic supplements in peri-menopausal women. Surprisingly, old macaque females maintained estrogen receptor expression, and long-term estradiol supplementation only marginally influenced the receptor density (Naugle et al. 2014). In humans, there is evidence that brain masculinization is AR (androgen-receptor)-mediated rather than ER-mediated but the issue remains controversial (Luoto and Rantala 2018; MottaMena and Puts 2017; Puts and Motta-Mena 2018).

The impact of estrogen on the central dopaminergic system and on the brain reward system is also significant. Menopausal women more often exhibit symptoms of Parkinson and schizophrenia diseases, which are related to decreased dopamine production or transmission rates compared to individuals with cycling estrogen fluctuations (Cyr et al. 2002). Moreover, decreased dopamine release also seems to be related to the development of drug addiction. Accordingly, Lynch et al. (2002) indicated that in adults drug abuse is more likely in males than in females; in adolescent individuals, however, drug addiction is only marginally different between the sexes. Studies of selfadministration of alcohol in rats and vervet monkeys showed that females consume higher amounts of alcohol than males. In rhesus macaques, however, the sex difference was reversed (Lynch et al. 2002). Short-term self-administration of heroin did not differ in in male and females rats. In contrast, extended access to this drug was associated with higher self-administration in females (Lynch et al. 2002). Cycling women show a dependence of euphoria on $d$-amphetamine with regard to behaviors such as liking, wanting, or energy, and intellectual improvements during later follicle periods (Justice and de Wit 1999). Moreover, estradiol seems to improve subjective feelings of pleasure and feeling "high" in association with amphetamine (Sofuoglu et al. 1999). Nicotine withdrawal, instead, correlated with premenstrual symptoms during the late luteal phase of the cycle (Allen et al. 2000). These and other studies have shown that estradiol decreases the dopamine reuptake and therefore increases dopamine concentration in the synaptic cleft. This accelerates the binding rate for dopamine at D1 and D2 receptors, while reducing it for D3 receptors in the mesolimbic reward system (see Almey et al. 2015). Ultrastructural analyses of estrogen receptors within dopamine terminal regions such as the medial prefrontal cortex identified such receptors in extranuclear sites of neurons and glia; the highest densities were recorded at axons and terminals (Almey et al. 2014).

The described neuro-circuitry of the reward system, which includes the interplay between the dopaminergic system and estrogen, also plays a significant role in female decision making. In one study of rats, females were tested using an effort-discounting task with different types of reward: pressing a lever once yielded two pellets, pressing it many more times yielded four pellets. The results showed that ovariectomized females 
expressed a preference for the high-reward lever, whereas females treated with estradiol selected the low-reward lever. Moreover, the application of ER $\alpha$ receptor agonists, independently of ER $\beta$ agonists, resulted in high reward/high cost preferences, but simultaneous application of agonists for both receptor types decreased the choice for such high benefit/high cost options (Uban et al. 2012).

In addition to the dopaminergic system, it is important to consider also estrogen effects on the serotonergic brain system in relation to female sexual behavior. Introducing ovarian hormones into the dorsal raphe nuclei region of macaque brains altered the mRNA expression rates of components involved in serotonin metabolism (PecinsThompson et al. 1998). The rhombencephalic raphe nuclei complex is the origin of the serotonergic system. From here serotonergic fibers project into almost all brain areas (Holloway et al. 1993). Lower brain serotonin concentrations are related, for example, to depression, anxiety, and impaired cognition (Wallner and Machatschke 2009). Application of estrogen with or without progesterone increased tryptophan hydroxylase-I mRNA, but decreased mRNAs of MOA-A and concentrations of the serotonin re-uptake transporter. The latter impairs the relocation of serotonin metabolites from the postsynaptic membrane into presynaptic regions. All of these manipulations affect central serotonergic function (Smith et al. 2004), and serotonergic pathways are known to influence fluctuations in female mood and behavior during the menstrual cycle.

From neurophysiological research we conclude that the actions of estrogen and its related receptor system in the brain influence female behavior in a socio-sexual context. The distribution rate and density of receptor fields in subcortical brain areas enable estrogens to exert a major influence on female sexuality, food intake, mood changes, feelings of pleasure, and cognitive function in different phase of the cycles, in which estrogen concentrations vary significantly.

\section{Conclusion}

Women share with nonhuman primates subcortical brain areas, which are essential to modulate behavioral and physiological changes in relation to different reproductive cycle stages. These homologous regions represent evolutionarily conserved structures documented in nearly all vertebrates. The interconnected social behavior network and the mesolimbic reward system are responsible for a basic integration of sexual behavior and its related reward sensations. These sensations are not limited to sexuality, but also include food intake (Adam and Epel 2007) and prosocial interactions (Rilling 2011). Here, emotional rewards are produced mainly via the dopaminergic system. Research on rhesus macaques has revealed two types of dopamine neurons, one excited by reward-predicting stimuli and the other inhibited by punishment-predicting stimuli (in this case, an airpuff). Importantly, more neurons are excited by both stimuli combined (Matsumoto and Hikosaka 2009). These results indicate that the dopamine system can differentiate between positive and negative signals. Matsumoto and Hikosaka (2009) proposed the existence of two functionally distinct dopamine neurons, the airpuffinhibited and the airpuff-excited type. They would be located in subcortical brain areas belonging to the mesolimbic reward system. In mammals, the mesolimbic reward system and other dopaminergic systems project to the prefrontal cortex, but the 
innervation density of the cortical striatum differs between humans and nonhuman primates (Raghanti et al. 2008). Moreover, the distribution of estradiol receptors in subcortical (Gonzales et al., 2007) and cortical areas suggests that value-oriented signals can be transformed into distinctive behaviors modulated by estradiol concentrations during different cycle phases. Such hormonal modulations are apparently homologous and stable in physiological and behavioral expression rates across species (Uban et al. 2012). Regardless of differences in the ways in which some primate species advertise or conceal ovulation, there may still be functional similarities in the way sexual stimuli are perceived, processed, and communicated. One important difference between humans and other primates may concern women's strategic behavioral decisions in relation to their fertility. Women have to make sure that the prospective fathers of their children are able and willing to invest significant resources in themselves and their children to an extent that is rarely observed in nonhuman primates.

Pair-bonding mechanisms have evolved in humans to make possible cooperative investment in children between reproducing partners. Such social bonds, however, should not be confused with sexual monogamy. The earliest primate ancestors may have had a solitary lifestyle similar to that of nocturnal mammals. Their descendants adopted a multi-male, multi-female social system approximately 52 million years ago, and subsequently evolved pair-living and one-male groups (harems) approximately 16 million years ago. Across all primates, monogamy is a less frequent social system than harems or multi-male, multi-female societies (Shulez et al. 2011). Nonetheless, social bonding between the sexes is probably tighter in one-male units than in multi-male, multi-female groups. At the level of mechanisms, these bonds are mediated by the neuropeptides oxytocin and vasopressin, which are produced in the magnocellular neurons of the paraventricular and supraoptic nuclei of the hypothalamus. These neurons project into areas of the mesolimbic reward system, such as amygdala or hippocampus, and into regions of the social behavior network, such as the BNST or the POA (Meyer-Lindenberg et al. 2011). The projections into these subcortical brain areas suggest that social bonding mechanisms may be related to sexual activities, and in particular to their emotional positive rewards (Young and Wang 2004). Both brain areas are evolutionarily relatively old. Therefore, we suggest that the neural circuits regulating sex - its emotional positive reward in relation to pair-bonding - were established after the evolution of single-male units in humans and nonhuman primates. This means that the origin of advertising female sexually attractive signals is older and originated in multi-male, multi-female primate societies.

Women's pre-fertilization selection process for socially compatible and genetically valuable partners with high status and resources is time-consuming and subject to female-female mating competition. Women's fat reserves, which are needed for succesful ovulation, gestation, and lactation, can contribute to permanent signals of sexual attractivenss such as large breasts and buttocks, which may signal physical and genetic fitness. Such permanent sexual signaling may allow females lengthier periods of mate assessment and more opportunities for mate choice without losing the interest of prospective partners. Studies have shown that men find attractive particular values of the waist-to-hip ratio as well as of the body mass index, which signals general health (Singh 2002; see also Havlíček et al. 2015 and commentaries). Additionally, breast morphology and size in fertile females may enhance the sexual attractiveness of the so- 
called hourglass body shape in women (see Dixson 2009). A question may arise as to whether men can perceive changes in female SSC in relation to culture-specific norms such as using different clothing during different cycle phases. For example (see also 2.4), the water content and parenchymal tissue volume increase in women during the luteal period and decreases during menstruation. As wearing clothes is common in most human societies, men are probably unable to recognize subtle cyclic changes in women's bodies when these are covered by clothes. It is also unclear whether men can detect changes the bodies of women with whom they are in permanent, stable relationships. Male perception and interpretation of the information content of female SSC may result from direct comparison of their shape and size between women, independent of their cycle stage. Such individual differences may provide information about a woman's health or reproductive fitness. In this context the American College of Radiology classified different mammographic density stages based on the fat-toparenchymal tissue content in relation to the risk of developing cancer. Overall, a higher proportion of parenchymal tissue compared to fat is related to cancer (type $1, \leq$ $25 \%$ of parenchymal tissue; type $2, \leq 50 \%$; type $3, \leq 75 \%$; type $4, \geq 75 \%$ parenchymal tissue). This classification shows that the ratio can vary extremely. Therefore, the fat content of female SSC communicates information about health and energy resources available for reproduction and parental investment. But the attractiveness in particular breast sizes and/or shapes is not necessarily a fitness marker insofar as a significantly reduced fat proportion is related to less available energy resources and to increased health risks (see above). In this context, more subtle changes in other body parts during the cycle - the lipid content of the skin, the fat content of the thighs and abdomen, pigmentations, etc. - would provide significant information but they are presumably not reliably detectable by men, even those living in long-term partnerships.

Importantly, women do change their behavior in relation to cycle phases. Some of these changes are obviously linked to their culture. During periovulatory periods, women advertise their fertility not only by changing their gait, but also by wearing particular clothes and make-up; their consumer behavior and food consumption are also different. Advertising fertility through make-up or clothes would be analogous to cyclic changes in sexual swellings or face coloration in nonhuman primate females. Functionally, both the morphological changes in nonhuman primates and the behavioral strategies in humans are caused by female intra-sexual competition for valuable mates and by male mate choice. Interestingly, neither the morphological changes described in nonhuman primates nor the culture-specific behaviors of women seem to reliably signal fertility, ovulation, or readiness to mate: exaggerated swellings are also expressed during non-fertile cycle phases and sexy clothes can be worn by women in all phases of the cycle. Possibly, the culturally developed use of specific clothes to enhance and accentuate sexually attractive body areas in women can be interpreted as an example of culture - biology co-adaptation that better highlights permanently attractive SSC under competitive partner market conditions (Puts 2010).

If the female SSC of nonhuman primates and humans do not directly inform males about females' fertility, - they might, in some cases, signal females' genetic fitness and physical condition. For example, wearing particular clothes may allow women to make some of their attractive bodily characteristics, such as a thin waist and wide hips, more visible to men. Since women's preferences for clothes and men's preferences for body shapes are known to be different in relation to cultures and historical periods, a full 
understanding of female sexual signaling and male responses to it in humans requires the integration of biological and cultural analyses.

Acknowledgments Open access funding provided by University of Vienna. The authors thank the journal's editors Dario Maestripieri and David Puts and three anonymous referees for help with the revision of the manuscript. The first author dedicates this work to John Dittami (1949-2014), a friend and inspiration.

\section{Compliance with Ethical Standards}

Conflict of Interest On behalf of all authors, the corresponding author states that there is no conflict of interest.

Open Access This article is distributed under the terms of the Creative Commons Attribution 4.0 International License (http://creativecommons.org/licenses/by/4.0/), which permits unrestricted use, distribution, and reproduction in any medium, provided you give appropriate credit to the original author(s) and the source, provide a link to the Creative Commons license, and indicate if changes were made.

\section{References}

Adam, T. C., \& Epel, E. S. (2007). Stress, eating and the reward system. Physiology and Behavior, 91, 449458.

Allen, S. S., Hatsukami, D., Christianson, D., \& Brown, S. (2000). Effects of transdermal nicotine on craving, withdrawal and premenstrual symptomatology in short-term smoking abstinence during different phases of the menstrual cycle. Nicotine \& Tobacco Research, 2, 231-241.

Almey, A., Cannell, E., Bertram, K., Filardo, E., Milner, T. A., \& Brake, W. G. (2014). Medial prefrontal cortical estradiol rapidly alters memory system bias in female rats: ultrastructural analysis reveals membrane-associated estrogen receptors as potential mediators. Endocrinology, 155, 4422-4432.

Almey, A., Milner, T. A., \& Brake, W. G. (2015). Estrogen receptors in the central nervous system and their implication for dopamine-dependent cognition in females. Hormones and Behavior, 74, 125-138.

Anderson, M. L., \& Dixson, A. F. (2002). Sperm competition: motility and the midpiece in primates. Nature, 416, 496.

Archie, E. A., Altmann, J., \& Alberts, S. C. (2014). Costs of reproduction in a long-lived female primate: injury risk and wound healing. Behavioral Ecology and Sociobiology, 68, 1183-1193.

Barelli, C., Heistermann, M., Boesch, C., \& Reichard, U. H. (2007). Sexual swellings in wild white-handed gibbon females (Hylobates lar) indicate the probability of ovulation. Hormones and Behavior, 51, 221230.

Baum, M. J., Slob, A. K., de Jong, F. H., \& Westbroek, D. L. (1978). Persistence of sexual behavior in ovariectomized stumptail macaques following dexamethasone treatment or adrenalectomy. Hormones and Behavior, 11, 323-347.

Beach, F. A. (1976). Sexual attractivity, proceptivity, and receptivity in female mammals. Hormones and Behavior, 7, 105-138.

Beaulieu, J. M., \& Gainetdinov, R. R. (2011). The physiology, signaling, and pharmacology of dopamine receptors. Pharmacological Reviews, 63, 182-217.

Berridge, K. C., \& Kringelbach, M. L. (2008). Affective neuroscience of pleasure: reward in humans and animals. Psychopharmacology, 199, 457-480.

Bowen, D. J., \& Grunberg, N. E. (1990). Variations in food preference and consumption across the menstrualcycle. Physiology and Behavior, 47, 287-291.

Bradley, B. J., \& Mundy, N. I. (2008). The primate palette: the evolution of primate coloration. Evolutionary Anthropology, 17, 97-111.

Brauch, K., Pfefferle, D., Hodges, K., Möhle, U., Fischer, J., \& Heistermann, M. (2007). Female sexual behavior and sexual swelling size as potential cues for males to discern the female fertile phase in freeranging Barbary macaques (Macaca sylvanus) of Gibraltar. Hormones and Behavior, 52, 375-383. 
Bröder, A., \& Hohmann, N. (2003). Variations in risk taking behavior over the menstrual cycle. An improved replication. Evolution and Human Behavior, 24, 391-398.

Bullivant, S. B., Sellergren, S. A., Stern, K., Spencer, N. A., Jacob, S., Mennella, J. A., \& McClintock, M. K. (2004). Women's sexual experience during the menstrual cycle: Identification of the sexual phase by noninvasive measurement of luteinizing hormone. Journal of Sex Research, 41, 82-93.

Burleson, M. H., Trevathan, W. R., \& Gregory, W. L. (2002). Sexual behavior in lesbian and heterosexual women: relations with menstrual cycle phase and partner availability. Psychoneuroendocrinology, 27, 489-503.

Byars, S. G., Ewbank, D., Govindaraju, D. R., \& Stearns, S. C. (2009). Natural selection in a contemporary human population. Proceedings of the National Academy of Sciences USA, 107, 1787-1792.

Cappelletti, M., \& Wallen, K. (2016). Increasing women's sexual desire: the comparative effectiveness of estrogens and androgens. Hormones and Behavior, 78, 178-193.

Chambers, K. C., \& Phoenix, C. H. (1987). Differences among ovariectomized female rhesus macaques in the display of sexual-behavior without and with estradiol treatment. Behavioral Neuroscience, 101, 303-308.

Clutton-Brock, T. H., \& Harvey, P. H. (1976). Evolutionary rules and primate societies. In P. P. G. Bateson \& R. A. Hinde (Eds.), Growing points in ethology (pp. 195-237). Cambridge: Cambridge Univ. Press.

Cumming, P., Brown, E., Damsma, G., \& Fibiger, H. (1992). Formation and clearance of interstitial metabolites of dopamine and serotonin in the rat striatum: an in vivo microdialysis study. Journal of Neurochemistry, 59, 1905-1914.

Cyr, M., Galon, F., Morissette, M., \& Di Paolo, T. (2002). Estrogenic modulation of brain activity: implications for schizophrenia and Parkinson's disease. Journal of Psychiatry and Neuroscience, 27, $12-27$.

Czaja, J. A., \& Goy, R. W. (1975). Ovarian hormones and food-intake in female guinea-pigs and rhesusmonkeys. Hormones and Behavior, 6, 329-349.

Davidsen, L., Vistisen, B., \& Astrup, A. (2007). Impact of the menstrual cycle on determinants of energy balance: a putative role in weight loss attempts. International Journal of Obesity, 31, 1777-1785.

Dawson, S. J., Suschinsky, K. D., \& Lalumiere, M. L. (2012). Sexual fantasies and viewing times across the menstrual cycle: a diary study. Archives of Sexual Behavior, 41, 173-183.

de Araujo, I. E., Kringelbach, M. L., Rolls, E. T., \& Hobden, P. (2003). Representation of umami taste in the human brain. Journal of Neurophysiology, 90, 313-319.

Dixson, A. F. (1983). Observations on the evolution and behavioral significance of "sexual skin" in female primates. Advances in the Study of Behaviour, 13, 63-106.

Dixson, A. F. (1998). Primate sexuality: Comparative studies of the prosimians, monkeys, apes, and human beings. New York: Oxford University Press.

Dixson, A. F. (2009). Sexual selection and the origins of human mating systems. Oxford: Oxford University Press.

Dixson, A. F., Everitt, B. J., Herbert, J., \& Scruton, D. M. (1973). Hormonal and other determinants of sexual attractiveness and receptivity in rhesus and talapoin monkeys. In C. H. Phoenix (Ed.), Primate reproductive behavior (pp. 36-63). Basel: Karger.

Domb, L. G., \& Pagel, M. (2001). Sexual swellings advertise female quality in wild baboons. Nature, 410, 204-206.

Dorus, S., Evans, P. D., Wyckoff, G. J., Choi, S. S., \& Lahn, B. T. (2004). Rate of molecular evolution of the seminal protein gene SEMG2 correlates with levels of female promiscuity. Nature Genetics, 36, 13261329.

Dubuc, C., Coyne, S. P., \& Maestripieri, D. (2013). Effect of mating activity and dominance rank on male masturbation among free-ranging male rhesus macaques. Ethology, 119, 1006-1013.

Dubuc, C., William, L. A., Cascio, J., Lee, D. S., Maestripieri, D., Petersdorf, M., Winters, S., \& Higham, J. P. (2016). Who cares? Experimental attention biases provide new insights into a mammalian sexual signal. Behavioral Ecology, 27, 68-74.

Durante, K. M., \& Griskevicius, V. (2016). Evolution and consumer behavior. Current Opinion in Psychology, $10,27-32$.

Durante, K. M., Griskevicius, V., Hill, S. E., Perilloux, C., \& Li, N. P. (2010). Ovulation, female competition, and product choice: hormonal influences on consumer behavior. Journal of Consumer Research, 37, 921934.

Dye, L., \& Blundell, J. E. (1997). Menstrual cycle and appetite control: implications for weight regulation. Human Reproduction, 12, 1142-1151.

Farage, M. A., Neill, S., \& MacLean, A. B. (2009). Physiological changes associated with the menstrual cycle: a review. Obstetrical and Gynecological Survey, 64, 58-72. 
Feinberg, D. R., Jones, B. C., Law Smith, M. J., Moore, F. R., DeBruine, L. M., Cornwell, R. E., Hillier, S. G., \& Perrett, D. I. (2006). Menstrual cycle, trait estrogen level, and masculinity preferences in the human voice. Hormones and Behavior, 49, 215-222.

Fergani, C., Routly, J. E., Jones, D. N., Pickavance, L. C., Smith, R. F., \& Dobson, H. (2014). Activation of cells containing estrogen receptor alpha or somatostatin in the medial preoptic area, arcuate nucleus, and ventromedial nucleus of intact ewes during the follicular phase, and alteration after lipopolysaccharide. Biology of Reproduction, 91, 1-12.

Field, Y., Boyle, E. A., Telis, N., Gao, Z., Gaulton, K. J., Golan, D., Yengo, L., Rocheleau, G., Froguel, P., McCarthy, M. I., \& Pritchard, J. K. (2016). Detection of human adaptation during the past 2000 years. Science, 354, 760-764.

Fisher, H. E., Aron, A., \& Brown, L. L. (2006). Romantic love: a mammalian brain system for mate choice. Philosophical Transactions of the Royal Society of London B, 361, 2173-2186.

Fitzpatrick, C. L., Altmann, J., \& Alberts, S. C. (2015). Exaggerated sexual swellings and male mate choice in primates: testing the reliable indicator hypothesis in the Amboseli baboons. Animal Behaviour, 104, 175185.

Flanagan-Cato, L. M. (2011). Sex differences in the neural circuit that mediates female sexual receptivity. Frontiers in Neuroendocrinology, 32, 124-136.

Forrester-Knauss, C., Zemp Stutz, E., Weiss, C., \& Tschudin, S. (2011). The interrelation between premenstrual syndrome and major depression: results from a population-based sample. BMC Public Health, 11, 795.

Fowler, P. A., Casey, C. E., Cameron, G. G., Foster, M. A., \& Knight, C. H. (1990). Cyclic changes in composition and volume of the breast during the menstrual cycle, measured by magnetic resonance imaging. British Journal of Obstetrics and Gynaecology, 97, 595-602.

Gangestad, S. W., \& Thornhill, R. (2008). Human oestrus. Proceedings of the Royal Society of London B, 275, 991-1000.

Gangestad, S. W., Simpson, J. A., Cousins, A. J., Garver-Apgar, C. E., \& Christensen, P. N. (2004). Women's preferences for male behavioral displays change across the menstrual cycle. Psychological Science, 15, 203-207.

Garcia-Falgueras, A., Ligtenberg, L., Kruijver, F. P., \& Swaab, D. F. (2011). Galanin neurons in the intermediate nucleus (InM) of the human hypothalamus in relation to sex, age, and gender identity. Journal of Comparative Neurology, 519, 3061-3084.

Garver-Apgar, C. E., Gangestad, S. W., \& Thornhill, R. (2008). Hormonal correlates of women's mid-cycle preference for the scent of symmetry. Evolution and Human Behavior, 29, 223-232.

Georgiadis, J. R., \& Kringelbach, M. L. (2012). The human sexual response cycle: brain imaging evidence linking sex to other pleasures. Progress in Neurobiology, 98, 49-81.

Gerald, M. S., Waitt, C., Little, A. C., \& Kraiselburd, E. (2007). Females pay attention to female secondary sexual color: an experimental study in Macaca mulatta. International Journal of Primatology, 28, 1-7.

Gildersleeve, K., Haselton, M. G., \& Fales, M. R. (2014). Do women's mate preferences change across the ovulatory cycle? A meta-analytic review. Psychological Bulletin, 140, 1205-1259.

Girolami, L., \& Bielert, C. (1987). Female perineal swelling and its effects on male sexual arousal: on apparent sexual releaser in the chacma baboon (Papio ursinus). International Journal of Primatology, 8, 651-661.

Giros, B., \& Caron, M. G. (1993). Molecular characterization of the dopamine transporter. Trends in Pharmacological Sciences, 14, 43-49.

Goodall, J. (1986). The Chimpanzees of Gombe: Patterns of behavior. Cambridge: Harvard University Press.

Grammer, K., Renninger, L., \& Fischer, B. (2004). Disco clothing, female sexual motivation, and relationship status: is she dressed to impress? Journal of Sex Research, 41, 66-74.

Grebe, N. M., Thompson, M. E., \& Gangestad, S. W. (2016). Hormonal predictors of women's extra-pair vs. in-pair sexual attraction in natural cycles: Implications for extended sexuality. Hormones and Behavior, $78,211-219$.

Guéguen, N. (2012). Gait and menstrual cycle: ovulating women use sexier gaits and walk slowly ahead of men. Gait \& Posture, 35, 621-624.

Gundlah, C., Kohama, S. G., Mirkes, S. J., Garyfallou, V. T., Urbanski, H. F., \& Bethea, C. L. (2000). Distribution of estrogen receptor beta (ERbeta) mRNA in hypothalamus, midbrain and temporal lobe of spayed macaque: continued expression with hormone replacement. Molecular Brain Research, 76, 191204.

Harvey, S. M. (1987). Female sexual behavior: Fluctuations during the menstrual cycle. Journal of Psychosomatic Research, 34, 101-110.

Haselton, M. G., \& Gildersleeve, K. (2011). Can men detect ovulation? Current Directions in Psychological Science, 20, 87-92. 
Havlíček, J., Cobey, K. D., Barrett, L., Klapilová, K., \& Roberts, S. C. (2015). The spandrels of Santa Barbara? A new perspective on the peri-ovulation paradigm. Behavioral Ecology, 26, 249-1260.

Hofman, M. H., \& Swaab, D. F. (1989). The sexually dimorphic nucleus of the preoptic area in the human brain: a comparative morphometric study. Journal of Anatomy, 164, 55-72.

Holloway, R. L., Anderson, P. J., Defendini, R., \& Harper, C. (1993). Sexual dimorphism of the human corpus callosum from independent samples: relative size of the corpus callosum. American Journal of Physical Anthropology, 92, 481-498.

Hurst, A. C., Alquist, J. L., \& Puts, D. A. (2017). Women's fertility status alters other women's jealousy and mate guarding. Personality and Social Psychology Bulletin, 43, 191-203.

Jones, B. C., Hahn, A. C., Fisher, C. I., Wang, H., Kandrik, M., \& DeBruine, L. M. (2018a). General sexual desire, but not desire for uncommitted sexual relationships, tracks changes in women's hormonal status. Psychoneuroendocrinology, 88, 153-157.

Jones, B. C., Hahn, A. C., Fisher, C. I., Wang, H., Kandrik, M., Han, C., Fasolt, V., Morrison, D., Lee, A. J., Holzleitner, I. J., O’Shea, K. J., Roberts, C. S., Little, A. C., \& DeBruine, L. M. (2018b). No compelling evidence that preferences for facial masculinity track changes in women's hormonal status. Psychological Science, 29, 996-1005.

Jünger, J., Motta-Mena, N. V., Cardenas, R., Bailey, D., Rosenfield, K. A., Schild, C., Penke, L., \& Puts, D. A. (2018). Do women's preferences for masculine voices shift across the ovulatory cycle? Hormones and Behavior, 106, 122-134.

Junglen, S., Hedemann, C., Ellerbrok, H., Pauli, G., Boesch, C., \& Leendertz, F. H. (2010). Diversity of STLV-1 strains in wild chimpanzees (Pan troglodytes verus) from Côte d'Ivoire. Virus Research, 150, 143-147.

Justice, A. J., \& de Wit, H. (1999). Acute effects of d-amphetamine during the follicular and luteal phases of the menstrual cycle in women. Psychopharmacology, 145, 67-75.

Kendrick, K. M., \& Dixson, A. F. (1984). Ovariectomy does not abolish proceptive behaviour cyclicity in the common marmoset (Callithrix jacchus). Journal of Endocrinology, 101, 155-162.

Knott, C. D., Thompson, M. E., Stumpf, R. M., \& McIntyre, M. H. (2010). Female reproductive strategies in orangutans, evidence for female choice and counterstrategies to infanticide in a species with frequent sexual coercion. Proceedings of the Royal Society of London B, 277, 105-113.

Krems, J. A., Neel, R., Neuberg, S. L., Puts, D. A., \& Kenrick, D. T. (2016). Women selectively guard their (desirable) mates from ovulating women. Journal of Personality and Social Psychology, 110, 551-573.

Kringelbach, M. L. (2005). The human orbitofrontal cortex: linking reward to hedonic experience. Nature Reviews Neuroscience, 6, 691-702.

Küster, J., \& Paul, A. (1984). Female reproductive characteristics in semifree-ranging Barbary macaques (Macaca sylvanus L. 1758). Folia Primatologica, 43, 69-83.

Li, J. H., Yin, H. B., \& Wang, Q. S. (2005). Seasonality of reproduction and sexual activity in female Tibetan macaques (Macaca thibetana) at Huangshan, China. Acta Zoologica Sinica, 51, 365-375.

Li, J. H., Yin, H. B., \& Zhou, L. (2007). Non-reproductive copulation behavior among Tibetan macaques (Macaca thibetana) at Huangshan, China. Primates, 48, 64-72.

Lissner, L., Stevens, J., Levitsky, D. A., Rasmussen, K. M., \& Strupp, B. J. (1988). Variation in energy-intake during the menstrual-cycle - implications for food-intake research. American Journal of Clinical Nutrition, 48, 956-962.

Lu, A., Beehner, J. C., Czekala, N. M., \& Borries, C. (2012). Juggling priorities: female mating tactics in Phayre's leaf monkeys. American Journal of Primatology, 74, 471-781.

Luoto, S., \& Rantala, M. J. (2018). On estrogenic masculinization of the human brain and behavior. Hormones and Behavior, 97, 1-2.

Lynch, W. J., Roth, M. E., \& Carroll, M. E. (2002). Biological basis of sex differences in drug abuse: preclinical and clinical studies. Psychopharmacology, 164, 121-137.

Maestripieri, D. (2014). Night owl women are similar to men in their relationship orientation, risk-taking propensities, and cortisol levels: implications for the adaptive significance and evolution of eveningness. Evolutionary Psychology, 12, 130-147.

Manson, J. H., Perry, S., \& Parish, A. R. (1997). Non conceptive sexual behavior in bonobos and capuchins. International Journal of Primatology, 18, 767-786.

Matsumoto, M., \& Hikosaka, O. (2009). Two types of dopamine neuron distinctly convey positive and negative motivational signals. Nature, 459, 837-841.

Meyer-Lindenberg, A., Domes, G., Kirsch, P., \& Heinrichs, M. (2011). Oxytocin and vasopressin in the human brain: social neuropeptides for translational medicine. Nature Reviews Neuroscience, 12, 524-538.

Michael, R. P., Clancy, A. N., \& Zumpe, D. (2005). Mating activates estrogen receptor-containing neurons in the female monkey brain. Physiology and Behavior, 85, 404 413. 
Missale, C., Nash, S. R., Robinson, S. W., Jaber, M., \& Caron, G. C. (1998). Dopamine receptors: from structure to function. Physiological Reviews, 78, 189-225.

Möhle, U., Heistermann, M., Dittami, J., Reinberg, V., Wallner, B., \& Hodges, J. K. (2005). Patterns of anogenital swelling size and their endocrine correlates during ovulatory cycles and early pregnancy in free-ranging barbary macaques (Macaca sylvanus) of Gibraltar. American Journal of Primatology, 66, 351-368.

Morris, N. M., Udry, J. R., Khan-Dawood, F., \& Dawood, M. Y. (1987). Marital sex frequency and midcycle female testosterone. Archives of Sexual Behavior, 16, 27-37.

Motta-Mena, N. V., \& Puts, D. A. (2017). Endocrinology of human female sexuality, mating, and reproductive behavior. Hormones and Behavior, 91, 19-35.

Nadler, R. D., Graham, C. E., Gosselin, R. E., \& Collins, D. C. (1985). Serum levels of gonadotropins and gonadal steroids, including testosterone, during the menstrual cycle of the chimpanzee (Pan troglodytes). American Journal of Primatology, 9, 273-284.

Naugle, M. M., Nguyen, L. T., Merceron, T. K., Filardo, E., Janssen, W. G., Morrison, J. H., Rapp, P. R., Gore, A. C., et al. (2014). G-protein coupled estrogen receptor, estrogen receptor $\alpha$, and progesterone receptor immunohistochemistry in the hypothalamus of aging female rhesus macaques given long-term estradiol treatment. Journal of Experimental Zoology. Part A, Ecological Genetics and Physiology, 321, 399-414.

Necka, E. A., Puts, D. A., Dimitroff, S. J., \& Norman, G. J. (2016). Other women's fertility moderates female resource distribution across the menstrual cycle. Evolution and Human Behavior, 37, 387-391.

Necka, E. A., Faig, K. E., Van Hedger, K., Lyons, I. M., Dimitroff, S. J., Luhmann, M., Puts, D. A., \& Norman, G. J. (2018). Women's attention to and memory for fertile- and non-fertile phase women across the menstrual cycle. Adaptive Human Behavior and Physiology, 4, 283-305.

Nepomnaschy, P. A., Welch, K., McConnell, D., Strassmann, B. I., \& England, B. G. (2004). Stress and female reproductive function: a study of daily variations in cortisol, gonadotrophins, and gonadal steroids in a rural Mayan population. American Journal of Human Biology, 16, 523-532.

Nunn, C. L., Gittleman, J. L., \& Antonovics, J. (2000). Promiscuity and the primate immune system. Science, 290, 1168-1170.

O'Connell, L. A., \& Hofmann, H. A. (2011). The vertebrate mesolimbic reward system and social behavior network: a comparative synthesis. Journal of Comparative Neurology, 519, 3599-3639.

Pagel, M. (1994). Evolution of conspicuous estrous advertisement in Old World monkeys. Animal Behaviour, 47, 1333-1341.

Patchev, A. V., Götz, F., \& Rohde, W. (2004). Differential role of estrogen receptor isoforms in sex-specific brain organization. The FASEB Journal, 18, 1568-1570.

Pawlowski, B. (1999). Loss of oestrus and concealed ovulation in human evolution. Current Anthropology, 40, 257-267.

Pecins-Thompson, M., Brown, N. A., \& Bethea, C. L. (1998). Regulation of serotonin re-uptake transporter mRNA expression by ovarian steroids in rhesus macaques. Molecular Brain Research, 53, 120-129.

Perin, F., Pittet, J. C., Schnebert, S., Perrier, P., Tranquart, F., \& Beau, P. (1999). Ultrasonic assessment of variations in thickness of subcutaneous fat during the normal menstrual cycle. European Journal of Ultrasound, 11, 7-14.

Petralia, S. M., \& Gallup, G. G., Jr. (2002). Effects of a sexual assault scenario on handgrip strength across the menstrual cycle. Evolution and Human Behavior, 23, 3-10.

Pflüger, L. S., Valuch, C., Gutleb, D. R., Ansorge, U., \& Wallner, B. (2014). Colour and contrast of female faces: attraction of attention and its dependence on male hormone status in Macaca fuscata. Animal Behaviour, 94, 61-71.

Pillsworth, E. G., Haselton, M. G., \& Buss, D. M. (2004). Ovulatory shifts in female sexual desire. Journal of Sex Research, 41, 55-65.

Puts, D. A. (2010). Beauty and the beast: mechanism of sexual selection in humans. Evolution and Human Behavior, 31, 157-175.

Puts, D. A., \& Motta-Mena, N. V. (2018). Is human brain masculinization estrogen receptor-mediated? Reply to Luoto and Rantala. Hormones and Behavior, 97, 3-4.

Puts, D. A., Bailey, D. H., Cardenas, R. A., Burriss, R. P., Welling, L. L., Wheatley, J. R., \& Dawood, K. (2013). Women's attractiveness changes with estradiol and progesterone across the ovulatory cycle. Hormones and Behavior, 63, 13-19.

Raghanti, M. A., Stimpson, C. D., Marcinkiewicz, J. L., Erwin, J. M., Hof, P. R., \& Sherwood, C. C. (2008). Cortical dopaminergic innervation among humans, chimpanzees, and macaque monkeys: a comparative study. Neuroscience, 31, 203-220.

Richerson, P. J., Boyd, R., \& Henrich, J. (2010). Gene-culture coevolution in the age of genomics. Proceedings of the National Academy of Sciences USA, 107, 8985-8992. 
Rilling, J. K. (2011). The neurobiology of cooperation and altruism. In R. W. Sussman \& C. R. Cloninger (Eds.), Origins of altruism and cooperation (pp. 295-306). New York: Springer.

Roney, R. J., \& Simmons, Z. L. (2016). Within-cycle fluctuations in progesterone negatively predict changes in both in-pair and extra-pair desire among partnered women. Hormones and Behavior, 81, 45-52.

Roney, J. R., \& Simmons, Z. L. (2017). Ovarian hormone fluctuations predict within-cycle shifts in women's food intake. Hormones and Behavior, 90, 8-14.

Rudebeck, P. H., \& Murray, E. A. (2011). Balkanizing the primate orbitofrontal cortex: distinct subregions for comparing and contrasting values. Annals of the New York Academy of Sciences, 1239, 1-13.

Rudski, J. M., Bernstein, L. R., \& Mitchell, J. E. (2011). Effects of menstrual cycle phase on ratings of implicitly erotic art. Archives of Sexual Behavior, 40, 767-773.

Rushmore, J., Allison, A. B., Edwards, E. E., Bagal, U., Altizer, S., Cranfield, M. R., Glenn, T. C., Liu, H., Mudakikwa, A., Mugisha, L., Muller, M. N., Stumpf, R. M., Thompson, M. E., Wrangham, R., Yabsley, M. J., et al. (2015). Screening wild and semi-free ranging great apes for putative sexually transmitted diseases: evidence of trichomonadidae infections. American Journal of Primatology, 77, 1075-1085.

Schober, J. M., \& Pfaff, D. (2007). The neurophysiology of sexual arousal. Best Practice \& Research Clinical Endocrinology \& Metabolism, 21, 445-461.

Setchell, J. M., Charpentier, M. J. E., Bedjabaga, I. B., Reed, P., Wickings, E. J., \& Knapp, L. A. (2006a). Secondary sexual characters and female quality in primates. Behavioral Ecology and Sociobiology, 61, 305-315.

Setchell, J. M., Wickings, E. J., \& Knapp, L. A. (2006b). Signal content of red facial coloration in female mandrills (Mandrillus sphinx). Proceedings of the Royal Society of London B, 273, 2395-2400.

Shirazi, T. N., Self, H., Dawood, K., Rosenfield, K. A., Penke, L., Carré, J. M., Ortiz, T., \& Puts, D. A. (2019). Hormonal predictors of human sexual motivation. Evolution and Human Behavior, https://doi. org/10.1016/j.evolhumbehav.2019.02.002.

Shively, C. A., \& Bethea, L. (2004). Cognition, mood disorders, and sex hormones. Institute for Laboratory Animal Resources Journal, 45, 189-199.

Shively, C. A., Williams, J. K., Laber-Laird, K., \& Anton, R. F. (2002). Depression and coronary artery atherosclerosis and reactivity in female cynomolgus monkeys. Psychosomatic Medicine, 64, 699-706.

Shulez, S., Opie, C., \& Atkinson, Q. D. (2011). Stepwise evolution of stable sociality in primates. Nature, 479, 219-222.

Singh, D. (2002). Female mate value at a glance: relationship of waist-to-hip ratio to health, fecundity and attractiveness. Neuro Endocrinology Letters, 23, 81-91.

Smith, E. M. (1999). High heels and evolution. Psychology, Evolution and Gender, 1, 245-277.

Smith, L. J., Henderson, J. A., Creed, W., Abell, C. W., \& Bethea, C. L. (2004). Effects of ovarian steroids and raloxifene on proteins that synthesize, transport, and degrade serotonin in the raphe region of macaques. Neuropsychopharmacology, 29, 2035-2045.

Sofuoglu, M., Dudish-Poulsen, S., Nelson, D., Pentel, P. R., \& Hatsukami, D. K. (1999). Sex and menstrual cycle differences in the subjective effects from smoked cocaine in humans. Experimental and Clinical Psychopharmacology, 7, 274-283.

Stumpf, R. M., \& Boesch, C. (2006). The efficacy of female choice in chimpanzees of the Taï Forest, Côte d'Ivoire. Behavioral Ecology and Sociobiology, 60, 749-765.

Uban, K. A., Rummel, J., Floresco, S. B., \& Galea, L. A. (2012). Estradiol modulates effort-based decision making in female rats. Neuropsychopharmacology, 37, 390-401.

Uphouse, L. (2014). Pharmacology of serotonin and female sexual behavior. Pharmacology Biochemistry and Behavior, 121, 31-42.

Vasey, P.L., \&, Duckworth, N. (2006). Sexual reward via vulvar, perineal, and anal stimulation: a proximate mechanism for female homosexual mounting in Japanese macaques. Archives of Sexual Behavior, 35 , $523-532$.

Voytko, M. L. (2002). Estrogen and the cholinergic system modulate visuospatial attention in monkeys (Macaca fascicularis). Behavioral Neuroscience, 116, 187-197.

Wallen, K., \& Zehr, J. L. (2004). Hormones and history: the evolution and development of primate female sexuality. Journal of Sex Research, 41, 101-112.

Wallis, J. (1982). Sexual behavior of captive chimpanzees (Pan troglodytes): pregnant versus cycling females. American Journal of Primatology, 3, 77-88.

Wallis, J. (1992). Chimpanzee genital swelling and its role in the pattern of sociosexual behavior. American Journal of Primatology, 28, 101-113.

Wallner, B., \& Machatschke, I. H. (2009). The evolution of violence in men: the function of central cholesterol and serotonin. Progress in Neuro-Psychopharmacology \& Biological Psychiatry, 33, 391-397. 
Wallner, B., Prossinger, H., \& Mostl, E. (1999). Perineal swellings: a social and endocrine advantage for Barbary macaque fermales (Macaca sylvanus). Collegium Antropologicum, 23, 451-459.

Wallner, B., Dittami, J., \& Wallis, J. (2006). Influence of perineal swellings on behavior and stress reaction in levonorgestrel implanted Macaca sylvanus females. Neuroendocrinology Letters, 27, 253-256.

Wallner, B., Aspernig, D., Millesi, E., \& Machatschke, I. H. (2011). Non-lactating versus lactating females: a comparison of sex steroids, sexual coloration, and sexual behavior in Japanese macaques. Primates, 52, 69-75.

Waytz, A., Jamil Zaki, J., \& Mitchell, J. P. (2012). Response of dorsomedial prefrontal cortex predicts altruistic behavior. Journal of Neuroscience, 32, 7646-7650.

Wikenheiser, A. M., \& Schoenbaum, G. (2016). Over the river, through the woods: cognitive maps in the hippocampus and orbitofrontal cortex. Nature Reviews Neuroscience, 17, 513-523.

Wildt, D. E., Doyle, L. L., Stone, S. C., \& Harrison, R. M. (1977). Correlation of perineal swelling with serum ovarian hormone levels, vaginal cytology, and ovarian follicular development during the baboon reproductive cycle. Primates, 18, 261-270.

Wlasiuk, G., \& Nachman, M. W. (2010). Promiscuity and the rate of molecular evolution at primate immunity genes. Evolution, 64, 2204-2220.

Wood, W., Kressel, L., Joshi, P. D., \& Louie, B. (2014). Meta-analysis of menstrual cycle effects on women's mate preferences. Emotion Review, 6, 229-249.

Young, L. J., \& Wang, Z. (2004). The neurobiology of pair bonding. Nature Neuroscience, 7, 1048-1054.

Publisher's Note Springer Nature remains neutral with regard to jurisdictional claims in published maps and institutional affiliations.

\section{Affiliations}

\section{Bernard Wallner ${ }^{1} \cdot$ Sonja Windhager ${ }^{2,3} \cdot$ Helmut Schaschl $^{2} \cdot$ Matthias Nemeth ${ }^{1}$. Lena S. Pflüger ${ }^{1,2}$ - Martin Fieder ${ }^{2}$ - Jacqueline Domjanić ${ }^{4}$ • Eva Millesi ${ }^{1} \cdot$ Horst Seidler $^{2}$}

\section{Bernard Wallner}

Bernard.wallner@univie.ac.at

1 Department of Behavioural Biology, University of Vienna, Vienna, Austria

2 Department of Evolutionary Anthropology, University of Vienna, Vienna, Austria

3 Department of Theoretical Biology, University of Vienna, Vienna, Austria

4 Department of Clothing Technology, University of Zagreb, Zagreb, Croatia 